Б.О. Демідов, Д.А. Гриб, С.І. Хмелевський, О.О. Хмелевська

Харківський національний університет Повітряних Сил ім. І. Кожедуба, Харків

\title{
МЕТОДИЧНІ ПІДХОДИ ДО СТВОРЕННЯ ПРОГРАМНИХ ДИНАМІЧНИХ СТАТИСТИЧНИХ ЕКВІВАЛЕНТІВ ЕЛЕМЕНТІВ ЗРАЗКІВ ОЗБРОЄННЯ I ВІЙСЬКОВОЇ ТЕХНІКИ
}

У статті розглядаються науково-методичні положення про обчислювальні експериментальні $і$ програмні динамічні статистичні еквіваленти (ДСЕ), щчо використовуються для створення імітаційних моделей складних зразків озброєння і військової техніки та їх програмного забезпечення. Наведена модель похибки вимірювань інформаційно-вимірювальної системи, щзо може бути корисною при заміні реального об'єкту ДСЕ, адекватним із точністю до заданих статистичних характеристик. Наводяться типові приклади, щяо підтверджують необхідність (дочільність) застосування вказаних методичних засобів при передпроєктних дослідженнях, зовнішньому проектуванні $i$ під час дослідження проблем обтрунтування $i$ вибору обрисів, передпроєктних конструкторських рішень і варіантів використання за призначенням нових зразків ОВТ і у тих випадках, коли створення цүих засобів здійснюється із значними витратами ресурсів.

Ключові слова: складні технічні системи, імітаційне моделювання та обчислювальні експерименти, статистичні еквіваленти, програмно-реалізований алгоритм, дослідно-теоретичні методи досліджень $i$ випробувань.

\section{Вступ}

Постановка проблеми. Для процесу створення і постачання у війська сучасних зразків озброєння і військової техніки (ОВТ) визначилась тенденція швидкого оновлення їх номенклатури з одночасним підвищенням наукоємності, технологічності та структурно-функціональної складності зразків, а також вартості засобів і робіт, що проводяться, це підняло вимоги до якості, зменшення термінів і вартості їх проєктування, конструкторського, програмного відпрацювання і вводу в експлуатацію.

Унікальність і складіть процесу створення зразків ОВТ потребує вирішення проблемних ситуацій вибору варіантів створення зразків ОВТ, і проведення вельми витратних їх випробувань: програмноапаратного моделювання в рамках досліднотеоретичного методу досліджень випробувань, лабораторні, натурні, у тому числі і стендові випробування, льотні в умовах реальної експлуатації і застосування за призначенням, та інші.

Аналіз останніх досліджень і публікацій. Декомпозиція загальної задачі розробки і одночасного відпрацювання зразків ОВТ потребує розгляду часткових задач: структурно-функціонального і алгоритмічного проєктування, розробки програмного забезпечення, конструювання, технологічного проєктування, перевірки і порівняння різних варіантів побудови зразків ОВТ з вибором з їх складу кращого варіанту [1-5].

У цьому процесі необхідно вирішити складну задачу створення імітаційних моделей для отримання даних ефективнісно-кваліметричного характеру та аналізу альтернативних варіантів створення (вдо- сконалення) зразків ОВТ, які дозволяють враховувати фактори якості (цільової реалізованості), часові і вартісні фактори, а також фактори ризику і похибок моделювання [6-7].

Імітаційні моделі $\epsilon$ основним засобом дослідження об'єктів у часі і просторі у ситуаціях, коли відсутня можливість математичної формалізації для аналітичного вирішення задачі опису функціонування об'єктів на усіх етапах (фазах) їх створення [3-7].

У межах моделювання проводяться обчислювальні електронні машинні експерименти, із великою кількістю комплексних розрахунків (“прогонів" моделі), до єдиного циклу яких входять наступні етапи:

- перехід від змістовного природнього опису до абстрактного - фізичного опису (фізичної моделі) об'єкту;

- перехід до математичного опису об'єкту (математичної моделі), розробка аналітичного апарату i алгоритмічної бази, адекватних до спектру задач обчислювального експерименту, створення програмного забезпечення;

- виконання серії модельних експериментів (“прогонів” моделі) і отримання та аналіз результатів прогонів моделі та їх інженерна інтерпретація [7-8].

Обчислювальний експеримент 3 використанням імітаційного стохастичного моделювання дозволяє суттєво доповнити відомі математичні і натурні методи та більш повно дослідити зразки ОВТ у цілому, значно звузити коло задач і робіт складних і багатовартісних експериментальних випробувань з перевіркою стійкості і перешкодостійкості їх функціонування у різних умовах [8-10]. 
Від якості проведення обчислювального експерименту залежить рівень ризику доведення зразків ОВТ до відповідних вимог ТТЗ у прийнятні терміни iз необхідним рівнем якості їх виконання.

Досить розповсюдженим методом відпрацювання (тестування) програмно-реалізованих алгоритмів функціонування зразків на етапах їх створення є метод формування вхідних (зовнішніх) впливів на досліджуваний фрагмент програмно-реалізованого алгоритму функціонування (управління) об'єкту із використанням динамічних статистичних еквівалентів.

Цей метод дозволяє суттєво підвищити швидкодію моделей, скоротити терміни їх розробки, реалізувати модель функціонування об'єкту (окремої складової об'єкту) без розкриття усього внутрішнього механізму функціонування об'єкту [2].

Мета статті - у змістовно-формалізованому вигляді подати і виокремити основні елементи процедури побудови і застосування за призначенням програмно-реалізуємих динамічних статистичних еквівалентів (ДСЕ), що формують вхідні впливи для тестування фрагментів алгоритмів і програм, що входять до складу інформаційного забезпечення функціонування створюваних зразків ОВТ.

\section{Виклад основного матеріалу}

Метод ДСЕ має певні переваги у модельному поданні процесів функціонування складних динамічних технічних систем (СДТС) у масштабі реального часу, що дозволяє спростити їх математичні моделі, і при цьому забезпечити прийнятну їх швидкодію i достовірність відтворення характеристик СДТС або окремих їх підсистем.

Для створення імітаційної моделі для опису процесу функціонування СДТС таких як зенітний ракетний комплекс (ЗРК), повітряне судно або радіоелектронний засіб (РЕ3), які функціонують у реальних умовах, необхідне залучення значних інтелектуальних, обчислювальних, часових і інших ресурсів. Відтворення процесу спільного і одночасного функціонування декількох СДТС для досягнення спільної мети, у режимі реального часу, з урахуванням значної кількості зовнішніх і внутрішніх факторів природнього і штучного характеру, суттєво залежить від швидкодії обчислювальних електронних засобів [2; 9-11]. Слід зазначити, що більшість 3 цих факторів мають стохастичну природу із відомими законами розподілу ймовірностей для певних умов $\mathrm{i}$ обмежень функціонування вказаних об'єктів.

Прикладом такої ситуації є моделювання процесу льотних випробувань зенітної керованої ракети (ЗКР) і налагоджування алгоритму (процесу) іiі наведення на ціль, коли у цьому процесі мають функціонувати усі вказані вище (і інші) СДТС, які на час проведення моделювання, наприклад у період передпроєктних досліджень, можуть бути не створе- ними [12-17].

Для функціонування таких моделей, на певних етапах їх розробки виникає необхідність імітації (еквівалентної заміни) деяких підсистем, або елементів створюваних зразків ОВТ їх модельними еквівалентами, які будуть забезпечувати вхідною інформацією (вхідними впливами) основну СДТС.

Для проведення моделювання у масштабі реального часу польоту ЗКР створюваного ЗРК виникає необхідність в імітації координат і параметрів руху цілі, що супроводжуються радіолокатором, що входить до складу ЗРК. Для імітації процесу отримання радіолокаційної інформації, процес вимірювання радіолокатором координат цілі 3 помилками, що близькі до очікуваних, може бути замінений програмно-апаратним ДСЕ, що відтворює його, з урахуванням випадковості процесу із заданими статистичними характеристиками [2-3].

Урахування особливостей контуру управління літальним апаратом у різних режимах функціонування моделі його управління також може бути забезпечено використанням програмно реалізованих ДСЕ, що враховують динамічні характерні управління літальних апаратів і засобів їх управління (електронні, електронно-механічні та інші) [12-13].

ДСЕ можуть застосовуватись для забезпечення точності результатів обчислювального експерименту при проектуванні складних СДТС різного призначення у тому числі і зразків (систем) ОВТ [2; 11].

Використання ДСЕ у комплексних стендах імітації систем протиракетної (ПРО) і протиповітряної (ППО) оборони для уточнення змін параметрів їх основних динамічних елементів (в першу чергу ЗКР) у реальному зовнішньому середовищі, дозволило розвити методи дослідно-теоретичної методології випробувань ракетного озброєння [13-14].

Математичні моделі, що представлені у вигляді програм реалізованих ДСО реальних об'єктів, у силу їх простоти забезпечують підвищення швидкодії моделей по відношенню до імітаційних моделей, більш придатні для використання при проведенні багатоваріантності аналізу СДТС. Вони дозволяють за прийнятний час прорахувати і порівняти між собою, за критерієм переваги, порівняно більшу кількість варіантів побудови створюваної системи, для відбору і виокремлення (обробкою) меншої кількості варіантів для більш детального моделювання i оперативного аналізу.

Може бути використаний ряд методів заміни реального об'єкту СДЕ, серед яких є метод генерації iз заміною процесу функціонування реального об'єкту генератором адекватного у статистичному смислі випадкового процесу, що відтворюються із точністю до заданих статистичних характеристик.

Типовим прикладом, що характерний для формування такого процесу, є процес формування по- 
хибки вимірювань інформаційно-вимірювальної системи (IBC), наприклад, радіолокаційних засобів (РЛЗ), що подається у вигляді моделі, яка відображає залежність похибки $\Delta_{j}$ вимірювань від факторів із деякою похибкою $\delta$ :

$$
\Delta_{j}=\mu\left(x_{j}\right)+\sigma\left(x_{j}\right) \zeta_{j}+\delta_{j}, \quad j=1 \ldots N,
$$

де $\mu(x)$ i $\sigma(x)$ - систематична похибка і середньо квадратичне відхилення відповідно, що розглядаються як функції вектору $x$, що визначають їх значення факторів;

$\zeta(t)$ - центрований і нормований випадковий процес $\quad(M[\zeta(t)]=0, D[\zeta(t)]=1, \quad M$ i $D \quad-$ математичне очікування і дисперсія відповідно);

$x_{j}$ - точки факторного простору;

$\zeta(t)$ - випадковий процес, що відображає спектральну структуру похибки;

$\delta$ - похибка, що видається моделлю похибок вимірювань IBC [15].

$\Delta_{j}$ - може розглядатись як похибка вимірювань координат цілі РЛС, оцінювання стану системи, результатів експерименту, випробування та інші.

Пошук залежності $\mu(x)$ i $\sigma(x)$ у виразі (1) будемо проводити у класі функцій, лінійних за параметрами із використанням математичного апарату теорії матиць і системного проєктування [15-17]. Представимо ці залежності у наступному вигляді:

$$
\begin{gathered}
\mu(x)=f^{\mathrm{T}}(x) a, \sigma(x)=g^{\mathrm{T}}(x) b, \\
\text { де } f(x)=\left(f_{0}(x), \ldots, f_{p}(x)\right)^{\mathrm{T}}, \\
g(x)=\left(g_{0}(x), \ldots, g_{r}(x)\right)^{\mathrm{T}}, \\
a=\left(a_{0}, \ldots, a_{r}\right)^{\mathrm{T}} i \quad b=\left(b_{0}, \ldots, b_{r}\right)^{\mathrm{T}}-\text { вектори сто- }
\end{gathered}
$$

вбці шуканих параметрів;

$f(x)$ і $g(x)$ - вектори стовбці заданих базисних функцій.

Нехай в області $\Omega_{x}$ факторного простору $X$ у відповідності до деякого плану експерименту (натурного або обчислювального) у точках $x_{j} \in \Omega_{x}, j=1 \ldots N$, проведений дослід і для кожної 3 них отримані $m$ значень оцінок похибок IBC:

$$
\Delta_{j l}=\mu\left(x_{j}\right)+\sigma\left(x_{j}\right) \zeta_{j l}, j=1 \ldots N, l=1 \ldots m,
$$

де $j$ - номер точки $x_{j}$ факторного простору $X$, що належить до спектру $x_{1}, \ldots, x_{j}, \ldots, x_{N}$ плану експерименту

$$
\left\{\begin{array}{c}
x_{1}, \ldots, x_{j}, \ldots, x_{N} \\
m_{1}, \ldots, m_{j}, \ldots, m_{N}
\end{array}\right\}, m_{1}=\ldots=m_{j}=\ldots=m_{N}=m,
$$

де $l$ - номер досліду у серії з $m$ дублюючих дослідів, що проводяться у кожній точці $x_{j}$ спектру плану експерименту.

При незалежних спостереженнях в межах серії та між серіями, тобто при

$$
\begin{gathered}
\mathrm{M}\left[\zeta_{i l} \zeta_{i v}\right]=0 \quad(i \neq j), \mathrm{M}\left[\delta_{i l} \delta_{i v}\right]=0,(i \neq j), \\
\mathrm{M}\left[\zeta_{i l} \delta_{i v}\right]=0,
\end{gathered}
$$

сукупність співвідношень (3) для кожного $l$ можна представити наступним чином:

$$
\mathrm{E}_{l}=\Phi \mathrm{A}+\mathrm{GBV}_{l}+\mathrm{Q}_{l},
$$

де $\quad \mathrm{E}_{l}=\left(\begin{array}{ccc}\Delta_{1 l} & \ldots & 0 \\ \cdot & \ldots & \cdot \\ \cdot & \ldots & \cdot \\ \cdot & \ldots & \cdot \\ 0 & \ldots & \Delta_{N 1}\end{array}\right)=\operatorname{diag}\left(\Delta_{1 l} \ldots \Delta_{N 1}\right)$

- діагональна матриця розміру $N \times N$;

$\Phi=\left(\begin{array}{ccc}f^{\mathrm{T}}\left(x_{1}\right) & \ldots & 0 \\ \cdot & \ldots & \cdot \\ \cdot & \ldots & \cdot \\ \cdot & \ldots & \cdot \\ 0 & \ldots & f^{\mathrm{T}}\left(x_{N}\right)\end{array}\right)=\operatorname{diag}\left(f^{\mathrm{T}}\left(x_{1}\right) \ldots f^{\mathrm{T}}\left(x_{N}\right)\right)$ - блочно-діагональна матриця розміру $N \times(p+1) N$ 3 блоками на діагоналі у вигляді вектор-строки

$$
f^{\mathrm{T}}\left(x_{j}\right)=\left(f_{0}\left(x_{j}\right), \ldots, f_{p}\left(x_{j}\right)\right), \quad j=1 \ldots N ;
$$$$
\mathrm{A}=\left(\begin{array}{ccc}
a & \ldots & 0 \\
\cdot & \ldots & \cdot \\
\cdot & \ldots & \cdot \\
\cdot & \ldots & \cdot \\
0 & \ldots & a
\end{array}\right)=\operatorname{diag}(a \ldots a)
$$

- блочно-діагональна матриця розміру $(p+1) N \times N$ 3 блоками на діагоналі у вигляді вектор-стовбця $a=\left(a_{0}, \ldots, a_{p}\right)^{\mathrm{T}}, \quad j=1 \ldots N$

$\mathrm{G}=\left(\begin{array}{ccc}g^{\mathrm{T}}\left(x_{1}\right) & \ldots & 0 \\ \cdot & \ldots & \cdot \\ \cdot & \ldots & \cdot \\ \cdot & \ldots & \cdot \\ 0 & \ldots & g^{\mathrm{T}}\left(x_{N}\right)\end{array}\right)=\operatorname{diag}\left(g^{\mathrm{T}}\left(x_{1}\right) \ldots g^{\mathrm{T}}\left(x_{N}\right)\right)$ - блочно-діагональна матриця розміру $N \times(r+1) N$ 3 блоками на діагоналі у вигляді вектор-строк $g^{\mathrm{T}}\left(x_{j}\right)=\left(g_{0}\left(x_{j}\right), \ldots, g_{r}\left(x_{j}\right)\right), \quad j=1 \ldots N$, 


$$
\mathrm{B}=\left(\begin{array}{ccc}
b & \ldots & 0 \\
\cdot & \ldots & \cdot \\
\cdot & \ldots & \cdot \\
\cdot & \ldots & \cdot \\
0 & \ldots & b
\end{array}\right)=\operatorname{diag}(b \ldots b)
$$

- блочно-діагональна матриця розміру $(r+1) N \times N$ 3 блоками на діагоналі у вигляді вектор-стовбців $b=\left(b_{0}, \ldots, b_{r}\right)^{\mathrm{T}}$;

$$
V_{l}=\left(\begin{array}{ccc}
\zeta_{1 l} & \ldots & 0 \\
\cdot & \ldots & \cdot \\
\cdot & \ldots & \cdot \\
\cdot & \ldots & \cdot \\
0 & \ldots & \zeta_{N l}
\end{array}\right)=\operatorname{diag}\left(\zeta_{1 l} \ldots \zeta_{N l}\right)
$$

- діагональна матриця розміру $N \times N$ [18].

Отримаємо вираз коваріаційної матриці оцінки вектору повної похибки вимірювань $\Delta_{j}=\left(\Delta_{1}, \ldots, \Delta_{N}\right)^{T}$.

$$
\mathrm{K}=\mathrm{M}\left\{\left[\mathrm{E}_{l}-\mathrm{M}\left(\mathrm{E}_{l}\right)\right]\left[\mathrm{E}_{l}-\mathrm{M}\left(\mathrm{E}_{l}\right)\right]^{T}\right\} .
$$

Для центрованого випадкового процесу $\zeta(t)$ :

$\mathrm{M}\left(V_{l}\right)=\operatorname{diag}\left(\mathrm{M}\left(\zeta_{1 l}\right) \ldots \mathrm{M}\left(\zeta_{N l}\right)\right)=\operatorname{diag}(0 \ldots 0)$.

При відсутності систематичної складової похибки $\delta(t)$ :

$$
\mathrm{M}\left(Q_{l}\right)=\operatorname{diag}\left(\mathrm{M}\left(\delta_{1 l}\right) \ldots \mathrm{M}\left(\delta_{N l}\right)\right)=\operatorname{diag}(0 \ldots 0) .
$$

Тому

$$
\begin{gathered}
\mathrm{M}\left(E_{l}\right)=\mathrm{M}\left(\Phi A+\mathrm{GBV}_{l}+\mathrm{Q}_{l}\right)= \\
\mathrm{M}(\Phi \mathrm{A})+\mathrm{GBM}\left(\mathrm{V}_{l}\right)+\mathrm{M}\left(\mathrm{Q}_{l}\right)=\Phi \mathrm{A}
\end{gathered}
$$

Тому

$$
\begin{gathered}
\mathrm{K}=\mathrm{M}\left[\left(\mathrm{E}_{1}-\mathrm{FA}\right)\left(\mathrm{E}_{1}-\mathrm{FA}\right)^{\mathrm{T}}\right]= \\
=\mathrm{M}\left[\left(\mathrm{GBV}_{1}+\mathrm{Q}_{1}\right)\left(\mathrm{GBV}_{1}+\mathrm{Q}_{1}\right)^{\mathrm{T}}\right]= \\
\mathrm{M}\left[\begin{array}{c}
\left.\left(\mathrm{GBV}_{1}\right)\left(\mathrm{GBV}_{1}\right)^{\mathrm{T}}+\mathrm{Q}_{1}\left(\mathrm{GBV}_{1}\right)^{\mathrm{T}}+\right]= \\
+\left(\mathrm{GBV}_{1}\right) \mathrm{Q}_{1}+\mathrm{Q}_{1} \mathrm{Q}_{1}^{\mathrm{T}}
\end{array}\right]= \\
\mathrm{GBM}\left(\mathrm{V}_{1} \mathrm{~V}_{1}^{\mathrm{T}}\right) \mathrm{B}^{\mathrm{T}} \mathrm{G}^{\mathrm{T}}+\mathrm{M}\left(\mathrm{Q}_{1} \mathrm{~V}_{1}^{\mathrm{T}}\right)^{\mathrm{T}}+ \\
+\mathrm{GBM}\left(\mathrm{V}_{1} \mathrm{Q}_{1}^{\mathrm{T}}\right)+\mathrm{M}\left(\mathrm{Q}_{1} \mathrm{Q}_{1}^{\mathrm{T}}\right) .
\end{gathered}
$$

3 прийнятих припущень про незалежність спостережень

$$
\mathrm{M}\left(\mathrm{V}_{1} \mathrm{Q}_{1}^{\mathrm{T}}\right)=\mathrm{M}\left(\mathrm{Q}_{1} \mathrm{~V}_{1}^{\mathrm{T}}\right)=0 \text { i } M\left(V_{l} V_{l}^{T}\right)=I,
$$

де $I-$ одинична матриця розміру $N \times N$.

Тому при $M\left(Q_{l} Q_{l}^{T}\right)=\delta^{2} I$

$$
\mathrm{K}=\delta^{2} \mathrm{I}+\mathrm{GBB}^{\mathrm{T}} \mathrm{G}^{\mathrm{T}} \text {. }
$$

При нормальному розподілі похибок вимірю- вань щільність розподілу імовірностей вектору повної похибки може бути представлена у наступному вигляді:

$$
\begin{aligned}
& f=(2 \pi)^{-\frac{N}{2}}\left|\delta^{2} \mathrm{I}=\mathrm{GBB}^{\mathrm{T}} \mathrm{G}^{\mathrm{T}}\right|^{-\frac{1}{2}} \\
& \exp \left\{-\frac{1}{2} \operatorname{tr}\left[\left(\delta^{2} \mathrm{I}+\mathrm{GBB}^{\mathrm{T}} \mathrm{G}^{\mathrm{T}}\right)^{-1} \times\left(\mathrm{E}_{l}-\Phi \mathrm{A}\right)\left(\mathrm{E}_{l}-\Phi \mathrm{A}\right)^{\mathrm{T}}\right]\right\} .
\end{aligned}
$$

Цьому відповідає функція правдоподібності і логарифм цієї функції

$$
\begin{gathered}
\mathrm{L}=(2 \pi)^{-\frac{m N}{2}}\left|\delta^{2} \mathrm{I}=\mathrm{GBB}^{\mathrm{T}} \mathrm{G}^{\mathrm{T}}\right|^{-\frac{m}{2}} \\
\exp \left\{-\frac{1}{2} \operatorname{tr}\left[\left(\delta^{2} \mathrm{I}+\mathrm{GBB}^{\mathrm{T}} \mathrm{G}^{\mathrm{T}}\right)^{-1} \times \sum_{l=1}^{m}\left(\mathrm{E}_{l}-\Phi \mathrm{A}\right)\left(\mathrm{E}_{l}-\Phi \mathrm{A}\right)^{\mathrm{T}}\right]\right\} \\
\ln \mathrm{L}=-\frac{m \mathrm{~N}}{2} \ln (2 \pi)-\frac{m}{2} \ln \left|\delta^{2} \mathrm{I}+\mathrm{GBB}^{\mathrm{T}} \mathrm{G}^{T}\right|- \\
\frac{1}{2} \operatorname{tr}\left[\left(\delta^{2} \mathrm{I}+\mathrm{GBB}^{\mathrm{T}} \mathrm{G}^{\mathrm{T}}\right)^{-1} \times \sum_{l=1}^{m}\left(\mathrm{E}_{l}-\Phi \mathrm{A}\right)\left(\mathrm{E}_{l}-\Phi \mathrm{A}\right)^{\mathrm{T}}\right] .
\end{gathered}
$$

Знайдемо похідну логарифму функції правдоподібності по матриці $B$. Для цього визначимо, що

$$
\frac{\partial \ln |\mathrm{C}|}{\partial \mathrm{C}}=\left(\mathrm{C}^{-1}\right)^{\mathrm{T}} \text {; }
$$

$$
\begin{gathered}
\frac{\partial\left[\operatorname{tr}\left(\mathrm{H}^{-1} \mathrm{U}\right)\right]}{\partial \mathrm{H}}=-\left(\mathrm{H}^{\mathrm{T}}\right)^{-1} \mathrm{U}\left(\mathrm{H}^{\mathrm{T}}\right)^{-1} ; \\
\frac{\partial\left[\mathrm{CDD}^{\mathrm{T}} \mathrm{C}^{\mathrm{T}}\right]}{\partial \mathrm{D}}=2 \mathrm{C}^{\mathrm{T}} \mathrm{CD},
\end{gathered}
$$

де $C, D, H, U$ - деякі матриці.

Шукана похідна

$$
\begin{aligned}
& \frac{\partial \ln \mathrm{L}}{\partial \mathrm{B}}=-m \mathrm{G}^{\mathrm{T}} \mathrm{GB}\left[\left(\mathrm{d}^{2} \mathrm{I}+\mathrm{GBB}^{\mathrm{T}} \mathrm{G}^{\mathrm{T}}\right)^{-1}\right]^{T}+ \\
& \mathrm{G}^{\mathrm{T}} \mathrm{GB}\left[\left(\delta^{2} \mathrm{I}+\mathrm{GBB}^{\mathrm{T}} \mathrm{G}^{\mathrm{T}}\right)^{-1} \times\right. \\
& \left.\sum_{l=1}^{m}\left(\mathrm{E}_{l}-\Phi \mathrm{A}\right)\left(\mathrm{E}_{l}-\Phi \mathrm{A}\right)^{\mathrm{T}}\left(\delta^{2} \mathrm{I}+\mathrm{GBB}^{\mathrm{T}} \mathrm{G}^{\mathrm{T}}\right)^{-1}\right]^{\mathrm{T}} .
\end{aligned}
$$

Дорівнявши похідну до нуля, після перетворень отримаємо

$$
\delta^{2} \mathrm{I}+\mathrm{GBB}^{\mathrm{T}} \mathrm{G}^{\mathrm{T}}=\frac{1}{m} \sum_{l=1}^{m}\left(\mathrm{E}_{l}-\Phi \mathrm{A}\right)\left(\mathrm{E}_{l}-\Phi \mathrm{A}\right)^{\mathrm{T}} .
$$

Представимо логарифм відношення правдоподібності (5) з урахуванням (6):

$$
\begin{gathered}
\ln \mathrm{L}=-\frac{m \mathrm{~N}}{2}\left(\ln \frac{m}{2 \pi}-1\right)- \\
-\frac{m}{2} \ln \left|\sum_{l=1}^{m}\left(\mathrm{E}_{l}-\Phi \mathrm{A}\right)\left(\mathrm{E}_{l}-\Phi \mathrm{A}\right)^{\mathrm{T}}\right| .
\end{gathered}
$$




$$
\Psi=\frac{m}{2} \ln \left|\sum_{l=1}^{m}\left(\mathrm{E}_{l}-\Phi\right)\left(\mathrm{E}_{l}-\Phi \mathrm{A}\right)^{\mathrm{T}}\right| .
$$

Перетворення виразу (8) з урахуванням того, що матриці є діагональними, дає

$$
\begin{aligned}
\Psi & =\frac{m}{2} \ln \prod_{j=1}^{N} \sum_{l}^{m}\left[\Delta_{j l}-f^{\mathrm{T}}\left(x_{j}\right) a\right]^{2}= \\
& =\frac{m}{2} \sum_{j=1}^{N} \ln \sum_{l}^{m}\left[\Delta_{j l}-f^{\mathrm{T}}\left(x_{j}\right) a\right]^{2} .
\end{aligned}
$$

Похідна $\Psi$ по параметрам $a_{v}, v=0 \ldots p$,

$$
\frac{\partial \Psi}{\partial a_{v}}=-\mathrm{m} \sum_{j=1}^{N} \frac{\sum_{l}^{m}\left[\Delta_{j l}-f^{\mathrm{T}}\left(x_{j}\right) a\right] f_{v}\left(x_{j}\right)}{\sum_{l}^{m}\left[\Delta_{j l}-f^{\mathrm{T}}\left(x_{j}\right) a\right]^{2}} .
$$

Дорівнявши похідну до нуля, отримаємо систему рівнянь

$$
\begin{gathered}
\sum_{j=1}^{N} \frac{f_{v}\left(x_{j}\right) \sum_{l=1}^{m} \Delta_{j l}}{\sum_{l}^{m}\left[\Delta_{j l}-f^{T}\left(x_{j}\right) a\right]^{2}}= \\
=\sum_{j=1}^{N} \frac{f_{v}\left(x_{j}\right) \sum_{l=1}^{m} f^{\mathrm{T}}\left(x_{j}\right) a}{\sum_{l=1}^{m}\left[\Delta_{j l}-f^{\mathrm{T}}\left(x_{j}\right) a\right]^{2}} \\
v=0 \ldots p,
\end{gathered}
$$

або

$$
\begin{gathered}
\sum_{j=1}^{N} \frac{\bar{\Delta}_{j} f\left(x_{j}\right)}{\frac{1}{m} \sum_{l=1}^{m}\left[\Delta_{j l}-f^{\mathrm{T}}\left(x_{j}\right) a\right]^{2}}= \\
=\sum_{j=1}^{N} \frac{f_{v}\left(x_{j}\right) f^{\mathrm{T}}\left(x_{j}\right) a}{\frac{1}{m} \sum_{l=1}^{m}\left[\Delta_{j l}-f^{\mathrm{T}}\left(x_{j}\right) a\right]^{2}},
\end{gathered}
$$

де $\bar{\Delta}_{j}=\frac{1}{m} \sum_{l=1}^{m} \Delta_{j l} \cdot 3$ того, що $\mathrm{M}\left[\Delta_{j l}\right]=f^{\mathrm{T}}\left(x_{j}\right) a$, то $\hat{\delta}_{j}^{2}=\frac{1}{m} \sum_{l=1}^{m}\left[\Delta_{j l}-f^{T}\left(x_{j}\right) a\right]^{2} \in$ оцінкою дисперсії $D\left(\Delta_{j}\right)$.

3 того, що $f^{T}\left(x_{j}\right) a$, то замість нього необхідно використовувати оцінку $\bar{\Delta}_{j}=\frac{1}{m} \sum_{l=1}^{m} \Delta_{j l}$.

Проведемо заміну $f\left(x_{j}\right) a$ оцінкою $\bar{\Delta}_{j}$, введемо незміщену оцінку дисперсії $\mathrm{D}\left(\Delta_{j}\right)$ :

$$
S_{j}^{2}=\frac{1}{m-1} \sum_{l=1}^{m}\left[\Delta_{j l}-\bar{\Delta}_{j}\right]^{2}, j=1 \ldots N,
$$

і перейдемо від системи рівнянь (10) до системи

$$
\sum_{j=1}^{N} \frac{\bar{\Delta}_{j} f_{v}\left(x_{j}\right)}{S_{j}^{2}}=\sum_{j=1}^{N} \frac{f_{v}\left(x_{j}\right) f^{\mathrm{T}}\left(x_{j}\right) a}{S_{j}^{2}}, \quad v=0 \ldots p .
$$

Ця система $є$ системою лінійних рівнянь відносно параметрів $a_{v}$. Якщо знайти їі рішення, можна знайти оцінку параметрів.

Якщо обрати план експерименту так, щоб

$$
\sum_{j=1}^{N} \frac{f_{i_{1}}\left(x_{j}\right) f_{i_{2}}\left(x_{j}\right)}{S_{j}^{2}}=0,
$$

при $i_{1} \neq i_{2}$, то формули оцінок параметрів $a_{v}$ набудуть більш простішого вигляду

$$
\hat{a}_{v}=\frac{\sum_{j=1}^{N} \frac{\bar{\Delta}_{j} f_{v}\left(x_{j}\right)}{S_{j}^{2}}}{\sum_{j=1}^{N} \frac{f_{v}^{2}\left(x_{j}\right)}{S_{j}^{2}}}, v=0 \ldots p .
$$

У відповідності з співвідношенням (6):

$$
\begin{aligned}
\delta^{2}+\left[\sum_{\mu=1}^{r} b_{\mu} g_{\mu}\left(x_{j}\right)\right]^{2} & =\frac{1}{m} \sum_{l=1}^{m}\left[\Delta_{j l}-f^{\mathrm{T}}\left(x_{j}\right) a\right]^{2} \\
j & =1 \ldots N .
\end{aligned}
$$

Змінимо праву частину (12) на $S_{j}^{2}$ і введемо міру наближеності значень $\sum_{\mu=0}^{r} b_{\mu} g_{\mu}\left(x_{j}\right)$ до $S_{j}$ на усьому спектрі плану експерименту у вигляді суми квадратів відхилень

$$
e=\sum_{j=1}^{N}\left[S_{j}-\sum_{\mu=0}^{r} b_{\mu} g_{\mu}\left(x_{j}\right)\right]^{2},
$$

методом найменших квадратів можна знайти оцінки параметрів $b_{\mu}, \mu=0 \ldots r$. Для цього необхідно вирішити систему рівнянь

$$
\frac{\partial e}{\partial b_{\mu}}=0, \mu=0 \ldots r .
$$

Слід зазначити, що проблема вибору виду базисних функцій $f(x)$ і $g(x)$, складу значущих факторів $x$ і відповідних параметрів $a$ і $b$ ДСЕ буде визначатись конкретним об’єктом, вихідні дані 3 відповідними характеристиками якого мають бути програмно відтворені як вхідні впливи для обробки фрагменту загальної спеціалізованої програми зразка ОВТ з урахуванням деякого компромісу між бажаним і реальним забезпечуваними (досяжними) вхідними впливами. Має забезпечуватись налаштування ДСЕ під конкретні вирішувані задачі опрацювання програмного забезпечення із прийнятною іiі 
якістю.

У цілому використання програмного реалізованих ДСЕ при вирішенні задачі опрацювання проєктів складних зразків ОВТ є корисним, навіть при додаткових витратах часових $n f$ інших ресурсів.

\section{Висновки}

Практична значущість використання ДСЕ разом із імітаційними моделями складних систем ОВТ при проведенні обчислювальних експериментів полягає у наданні дослідникам (розробникам) можливості зменшення часу на реалізацію у цих системах передових досягнень фундаментальних і прикладних наук для створення наукового здобутку, спростити моделі складних систем ОВТ, заощадити часові та інтелектуальні ресурси на передпроєктних стадіях досліджень і зовнішнього проєктування та забезпечити більш точне формування обрисів зразків OBТ. Разом з цим, створення ДСЕ на початкових стадіях їх програмного відтворення вимагатиме суттєвих витрат часу, інтелектуального і обчислювального ресурсів, але ці витрати будуть компенсовані під час досліджень і випробувань при неможливості проведення натурних експериментів і при проведенні обчислювального експерименту в рамках дослідно-теоретичного методу проєктування складних систем ОВТ.
На обчислювальний експеримент має покладатись забезпечення вирішення задач дослідження i синтезу складних систем за допомогою програмно реалізованих математичних моделей, що відображають найбільш важливі потрібні функціональні властивості різноманітних систем. Обчислювальний експеримент можна вважати вдалим, якщо отримані дані, достатні для прийняття рішення, щодо варіанту подальшої розробки зразка ОВТ. Раціональне поєднання використання швидкодіючих ДСЕ та імітаційних моделей, що мають меншу швидкодію, у цілому забезпечує зменшення часових витрат і покращення якості проведення варіантного аналізу проектів створюваних систем. У даному випадку процедура порівняльного аналізу альтернативних варіантів може бути подана як двоетапна процедура.

На першому етапі виконується оперативне виключення 3 пропозицій найменш конкурентних варіантів, за критерієм переваги. При цьому використання швидкодіючих ДСЕ дозволяє зменшити область пошуку необхідного варіанту для його наступної практичної реалізації. На другому етапі відокремлення оптимального варіанту може бути здійснено $з$ використанням менш швидкодіючих імітаційних моделей для більш точного і якісного порівняльного аналізу цих варіантів.

\section{Список літератури}

1. Основы военно-технических исследований. Теория и приложение : монография в 10 т. Т. 9. / Прикладные аспекты испытания и теоретико-экспериментальных исследований вооружения и военной техники / Чепков И. Б. и др. Киев : Изд. дом Д. Бураго, 2015. 504 с.

2. Программно-целевое планирование развития и научно-техническое сопровождение вооружения и военной техники. Кн. 3 / Демидов Б. А. и др.; под ред. Б. А. Демидова. Харьков : ХВУ, 1997. 551 с.

3. Методологічні й системотехнічні аспекти інформаційного забезпечення управління системами військового призначення та діяльності в оборонній сфері : монографія. Т. 1 / Велічко О. Ф. та ін. Київ : Стілос, 2021. 624 с.

4. Демидов Б. А., Величко А. Ф., Волощук И. В. Системно-концептуальные основы деятельности в военнотехнической области : в 3-х кн. Книга 3. Научно-методические основы деятельности в военно-технической области. Київ : Технологічний парк, 2019. 1312 с.

5. Системно-концептуальные основы методологии военно-научных исследований и решения прикладных военнонаучных проблем : в 3-х кн. Книга 3 / Демидов Б. А. и др. Тверь, 2014. 560 с.

6. Емельянов В. В. Имитационное моделирование систем. Москва : МГТУ им. Н.Э. Баумана, 2009. 584 с.

7. Девятков В. В. Методология и технология имитационных исследований сложных систем : современное состояние и перспективы развития. Москва : Вузовский учебник, ИНФРА, 2013. 448 с.

8. Мушек Э. Методы принятия технических решений / пер. с нем. Москва : Мир, 1990. 208 с.

9. Афанасьева Н. Ю. Вычислительные и экспериментальные методы научного эксперимента. Москва : КНОРУС, 2013. $330 \mathrm{c}$.

10. Тупиков К. А. Методы инженерного синтеза сложных систем управления. Часть 2. Вычислительноаналитический эксперимент : аппарат матричных операторов и вычислительные технологии. Москва : Изд-во им. Н.Э. Баумана, 2012. 416 с.

11. Ярош С. П. Теоретичні основи побудови та застосування розвідувально-управляючих інформаційних систем протиповітряної оборони : монографія. Харків : ХНУПС, 2012. 512 с.

12. Лебедев Г. Н. Системы управления летальными аппаратами. Москва : Изд-во МАИ, 2007. 756 с.

13. Тупиков К. А. Высокоточные системы самонаведения : расчет и проектирование. Вычислительный эксперимент. Москва : Физмат, 2011. 512 с.

14. Голубев И. С. Проектирование зенитных управляемых ракет. Москва : Изд-во МАИ, 2001. 732 с.

15. Ширман Я. Д. Радиоэлектронные системы: Основы построения и теория. Москва : Радиотехника, 2007. 512 с.

16. Гантмахер Ф. Р. Теория матриц. Москва : Физмат, 2009. 560 с.

17. Липаев В. В. Системное проектирование сложных программных средств для информационных систем. Изд. 2-е, перераб. и доп. Москва : СИНТЕГ, 2002. 268 с. 
Демідов Борис Олексійович доктор технічних наук професор провідний науковий співробітник Харківського національного університету Повітряних Сил ім. І. Кожедуба, Харків, Україна https://orcid.org/0000-0003-1728-6925

\section{Гриб Дмитро Анатолійович} кандидат військових наук доцент головний науковий співробітник Харківського національного університету Повітряних Сил ім. І. Кожедуба, Харків, Україна https://orcid.org/0000-0001-8478-978X

\section{Хмелевський Сергій Іванович}

кандидат технічних наук старший науковий співробітник начальник кафедри

Харківського національного університету

Повітряних Сил ім. І. Кожедуба,

Харків, Україна

https://orcid.org/0000-0001-6216-3006

\section{Хмелевська Ольга Олександрівна}

кандидат технічних наук старший науковий співробітник провідний науковий співробітник

Харківського національного університету

Повітряних Сил ім. І. Кожедуба,

Харків, Україна

https://orcid.org/0000-0001-9018-5552
Boris Demidov

Doctor of Engineering Science Professor

Leading Researcher

of Ivan Kozhedub Kharkiv National

Air Force University,

Kharkiv, Ukraine

https://orcid.org/0000-0003-1728-6925

\section{Dmitry Grib}

$\mathrm{PhD}$ in Military Science Associate Professor

Principal Researcher

of Ivan Kozhedub Kharkiv National

Air Force University,

Kharkiv, Ukraine

https://orcid.org/0000-0001-8478-978X

Serhii Khmelevskiy

$\mathrm{PhD}$ in Engineering Senior Researcher

Head of Department

of Ivan Kozhedub Kharkiv National

Air Force University,

Kharkiv, Ukraine

https://orcid.org/0000-0001-6216-3006

\section{Olga Khmelevska}

$\mathrm{PhD}$ in Engineering Senior Researcher

Leading Researcher

of Ivan Kozhedub Kharkiv National

Air Force University,

Kharkiv, Ukraine

https://orcid.org/0000-0001-9018-5552

\section{МЕТОДИЧЕСКИЕ ПОДХОДЫ К СОЗДАНИЮ ПРОГРАММНЫХ ДИНАМИЧЕСКИХ СТАТИСТИЧЕСКИХ ЭКВИВАЛЕНТОВ ЭЛЕМЕНТОВ ОБРАЗЦОВ ВООРУЖЕНИЯ И ВОЕННОЙ ТЕХНИКИ}

Б.А. Демидов, Д.А. Гриб, С.И. Хмелевский, О.А. Хмелевская

В статье обсуждаются научно-методические положения о вычислительных экспериментальных и программных динамических статистических эквивалентах (ДСЭ), используемых для создания имитационных моделей сложного вооружения и военной техники и их программного обеспечения. Представлена модель погрешности измерения информационно-измерительной системы, которая может быть полезна при замене реального объекта ДСЭ на адекватный заданным статистическим характеристикам. Приведены типовые примеры, подтверждающие необходимость (иелесообразность) использования данных методических средств в предпроектных проработках, внешнем проектировании и при изучении проблем обоснования и выбора вариантов предпроектных решений создания новых видов вооружения и военной техники и в случаях, когда создание этих средств требует значительных вложений ресурсов.

Ключевые слова: сложные технические системы, имитационное моделирование, статистические эквиваленты, программно-реализованный алгоритм, опытно-теоретические методы исследований и испытаний.

\section{METHODOLOGICAL APPROACHES TO THE CREATION OF SOFTWARE DYNAMIC STATISTICAL EQUIVALENTS OF ELEMENTS OF SAMPLES OF WEAPONS AND MILITARY EQUIPMENT}

B. Demidov, D. Grib, S. Khmelevskiy, O. Khmelevska

The article considers scientific and methodological provisions on computational experimental and software dynamic statistical equivalents used to create simulation models of complex samples of weapons and military equipment and their software. The obtained results help to develop and improve theoretical and experimental methods for determining the feasibility of using new physical principles, technical solutions and technological processes in the creation of promising and improvement of existing models, complexes and systems of weapons and military equipment. Providing researchers (developers) with the opportunity to reduce the time to implement in these systems the advanced achievements of basic and applied sciences to create scientific achievements, to simplify models of complex weapons systems and military equipment, pre-design stages of research and external designing and to ensure a more accurate formation of the outlines of samples of armaments and military equipment. The experiment can be considered successful if the data obtained are sufficient to decide on the option of further development of a sample of weapons and military equipment. A model of measurement error of the information-measuring system is given, which can be useful when replacing a real object of dynamic statistical equivalent, adequate to the specified statistical characteristics. The rational combination of the use of high-speed dynamic statistical equivalents and simulation models with lower speed, in general, reduces time costs and improves the quality of the variant analysis of projects of the created systems. The procedure of the comparative analysis of alternative variants which is presented in the form of two-stage procedure is offered. Typical examples are given that confirm the necessity (expediency) of the use of these methods in pre-design research, external design and during the study of problems of substantiation and choice of outlines, pre-design design solutions and options for the intended use of new models of weapons and military equipment and in cases where the creation of these tools is carried out with significant resource costs.

Keywords: complex technical systems, simulation modeling, statistical equivalents, software-implemented algorithm, research and theoretical methods of research and testing. 